University of South Florida

DIGITAL COMMONS

Digital Commons @ University of

@ UNIVERSITY OF SOUTH FLORIDA

South Florida

School of Geosciences Faculty and Staff

Publications

School of Geosciences

$9-2016$

\title{
The Record-Breaking 2015 Hurricane Season in the Eastern North Pacific: An Analysis of Environmental Conditions
}

\author{
Jennifer Collins \\ University of South Florida, collinsjm@usf.edu \\ Philip J. Klotzbach \\ Colorado State University \\ Ryan N. Maue \\ Weatherbell Analytics LLC \\ David R. Roache \\ University of South Florida \\ Eric S. Blake \\ National Hurricane Center, National Oceanic and Atmospheric Administrative
}

See next page for additional authors

Follow this and additional works at: https://digitalcommons.usf.edu/geo_facpub

Part of the Earth Sciences Commons

\section{Scholar Commons Citation}

Collins, Jennifer; Klotzbach, Philip J.; Maue, Ryan N.; Roache, David R.; Blake, Eric S.; Paxton, Charles H.; and Mehta, Christopher A., "The Record-Breaking 2015 Hurricane Season in the Eastern North Pacific: An Analysis of Environmental Conditions" (2016). School of Geosciences Faculty and Staff Publications. 1397.

https://digitalcommons.usf.edu/geo_facpub/1397

This Article is brought to you for free and open access by the School of Geosciences at Digital Commons @ University of South Florida. It has been accepted for inclusion in School of Geosciences Faculty and Staff Publications by an authorized administrator of Digital Commons @ University of South Florida. For more information, please contact digitalcommons@usf.edu. 


\section{Authors}

Jennifer Collins, Philip J. Klotzbach, Ryan N. Maue, David R. Roache, Eric S. Blake, Charles H. Paxton, and Christopher A. Mehta 


\section{Geophysical Research Letters}

\section{RESEARCH LETTER}

10.1002/2016GL070597

Collins and Klotzbach contributed equally to this work.

\section{Key Points:}

- Hurricane activity in the Western Development Region of the Eastern North Pacific broke records in 2015

- Record low vertical wind shear, record high relative humidity, low-level vorticity, and sea surface temperatures were primary contributors

- Strong El Nino and positive Pacific Meridional Mode provided conducive background environment

Correspondence to:

J. M. Collins,

collinsjm@usf.edu

\section{Citation:}

Collins, J. M., P. J. Klotzbach, R. N. Maue, D. R. Roache, E. S. Blake, C. H. Paxton, and C. A. Mehta (2016), The recordbreaking 2015 hurricane season in the eastern North Pacific: An analysis of environmental conditions, Geophys. Res. Lett., 43, 9217-9224, doi:10.1002/ 2016 GL070597.

Received 28 JUN 2016 Accepted 16 AUG 2016 Accepted article online 17 AUG 2016 Published online 2 SEP 2016

\section{The record-breaking 2015 hurricane season in the eastern North Pacific: An analysis of environmental conditions}

\author{
Jennifer M. Collins ${ }^{1}$, Philip J. Klotzbach ${ }^{2}$, Ryan N. Maue ${ }^{3}$, David R. Roache ${ }^{1}$, Eric S. Blake ${ }^{4}$, \\ Charles H. Paxton ${ }^{5}$, and Christopher A. Mehta ${ }^{1}$ \\ ${ }^{1}$ School of Geosciences, University of South Florida, Tampa, Florida, USA, ${ }^{2}$ Department of Atmospheric Science, Colorado \\ State University, Fort Collins, Colorado, USA, ${ }^{3}$ Weatherbell Analytics LLC, New York, New York, USA, ${ }^{4}$ National Hurricane Center, \\ National Oceanic and Atmospheric Administration, Miami, Florida, USA, ${ }^{5}$ National Weather Service, Ruskin, Florida, USA
}

Abstract The presence of a near-record El Niño and a positive Pacific Meridional Mode provided an extraordinarily warm background state that fueled the 2015 eastern North Pacific hurricane season to near-record levels. We find that the western portion of the eastern North Pacific, referred to as the Western Development Region (WDR; $10^{\circ}-20^{\circ} \mathrm{N}, 116^{\circ} \mathrm{W}-180^{\circ}$ ), set records for named storms, hurricane days, and Accumulated Cyclone Energy in 2015. When analyzing large-scale environmental conditions, we show that record warm sea surface temperatures, high midlevel relative humidity, high low-level relative vorticity, and record low vertical wind shear were among the environmental forcing factors contributing to the observed tropical cyclone activity. We assess how intraseasonal atmospheric variability may have contributed to active and inactive periods observed during the 2015 hurricane season. We document that, historically, active seasons are associated with May-June El Niño conditions, potentially allowing for predictability of future active WDR seasons.

\section{Introduction}

The eastern North Pacific basin is the most active region on Earth for tropical cyclone (TC) formation, when defined by genesis events per unit area and time [Molinari et al., 2000]. It has been well documented that modulations of the large-scale environment are typically responsible for above average or below average tropical cyclone seasons [Gray, 1979; Namias, 1954]. The 2015 eastern North Pacific hurricane season was notable for being extremely active, breaking many records, especially in the western part of the domain. Previously, Collins and Mason [2000] found it constructive to split the eastern North Pacific basin into two tropical cyclone development regions separated by $116^{\circ} \mathrm{W}$ : the eastern region, termed the Eastern Development Region (EDR), and the western region, termed the Western Development Region (WDR). The EDR was found by Collins and Mason [2000] to not exhibit any significant relationships, on an interannual timescale, with key dynamic and thermodynamic environmental parameters (such as El Niño-Southern Oscillation: ENSO) known to have an effect on tropical cyclone frequency in the Atlantic [Gray, 1979; Namias, 1954]. Mean atmospheric and oceanic conditions in the EDR are typically at or above the thresholds necessary for tropical cyclones to develop, accounting for the muted link to ENSO [Collins, 2007]. However, the WDR was found to have significant interannual variations in tropical cyclone activity, which is strongly linked to changes in thermodynamic parameters such as midtropospheric relative humidity, total precipitable water, and sea level pressure [Collins and Mason, 2000]. This paper focuses on the WDR and the extraordinary levels of activity that occurred there in 2015.

For tropical cyclone statistics listed throughout this manuscript, we count both systems that formed in the WDR or tracked into the WDR from the EDR. In 2015, the WDR had a total of 20 named storms (maximum 1 $\min , 10 \mathrm{~m}$ sustained winds $\geq 34$ knots, $(1 \mathrm{knot}=0.5 \mathrm{~m} / \mathrm{s}=1.85 \mathrm{~km} / \mathrm{h})$ ), 10 of which reached hurricane strength (maximum sustained winds $\geq 64$ knots) and six of which reached major hurricane strength (maximum sustained winds $\geq 96$ knots). Only 1992, with 21 named storms, eclipsed the total of 20 named storms observed in 2015. Ten hurricanes formed in 2015, tied with 1982 and 2014 as the fourth most on record (the most on record was 13, set in 1992). The six major hurricanes that occurred in 2015 trails behind 1992 which recorded seven major hurricanes. The 2015 hurricane season in the WDR set a record for Accumulated Cyclone Energy (ACE) [Bell et al., 2000], with $195 \times 10^{4} \mathrm{kt}^{2}$ being generated, eclipsing the old record of $182 \times 10^{4} \mathrm{kt}^{2}$ that was set in 1992. A total of 90 named storm days occurred in 2015, second only to 1992 which recorded 91.25 hurricane days. The 2015 WDR season set records for both hurricane 
days with 41.50 (old record was 40, set in 1992) and for major hurricane days with 18.5 (old record was 17, set in 1994).

The purpose of this paper is to show why the 2015 WDR hurricane season was extraordinarily active. This paper details the large-scale environmental factors associated with the variations in TC activity throughout the WDR for the 2015 season, including the large-scale forcing mechanisms in the WDR. We also examine how interannual variability driven by the Madden-Julian Oscillation (MJO) may have contributed to active and inactive periods that were observed in 2015. In addition, we show that using data since 1979, active WDR seasons are associated with late spring/early summer El Niño conditions, allowing for potential predictability of future hyperactive seasons.

\section{Data}

The HURDAT2 (HURricane DATa 2nd generation) database [Landsea and Franklin, 2013] (available online at http://www.aoml.noaa.gov/hrd/hurdat/Data_Storm.html) was utilized for WDR TC records from 1979 to 2014. This database presents a 6-hourly archive of TC intensity and location. Data are considered most reliable since 1988 in the eastern North Pacific when the National Hurricane Center took over operational responsibility from the National Weather Service office in Redwood City, California [Klotzbach and Landsea, 2015]. For 2015 data, we utilized operational best track data generated by the National Hurricane Center and Central Pacific Hurricane Center as archived by the University Corporation for Atmospheric Research (UCAR) located online at http://www.ral.ucar.edu/hurricanes/repository/data/bdecks_open/. We calculated the Accumulated Cyclone Energy (ACE) which is defined as the sum of the squares of the maximum sustained surface wind speed (knots) measured every $6 \mathrm{~h}$ for all named systems while they are at least tropical storm strength and not extratropical in phase [Bell et al., 2000].

For atmospheric and oceanic large-scale parameters, we utilize the ERA-Interim reanalysis products which are available from 1979 to present [Dee et al., 2011] and can be downloaded from http://www.ecmwf.int/en/ research/climate-reanalysis/era-interim. The reanalysis utilizes a four-dimensional variational data assimilation scheme to arrive at its globally gridded estimates of the observed weather conditions at a particular time. The spatial resolution of the data set is roughly $80 \mathrm{~km}$ (T255 spectral resolution), and the reanalysis is available on 60 vertical levels. ERA-Interim is utilized to rank all atmospheric fields from 1979 to 2015. SST data are obtained from the NOAA OISSTv2 data set $\left(0.25^{\circ}\right)$ [Reynolds et al., 2002] (available online at http://www. esrl.noaa.gov/psd/data/gridded/data.noaa.oisst.v2.html). This data set is only available since October 1981, so rankings for SST are from 1982 to 2015.

The climatological base period for SST is 1983 to 2012, as opposed to the current NOAA definition of $1981-2010$, as the NOAA OI SST $\left(0.25^{\circ}\right)$ data set quality is not as reliable in 1981-1982. Climatological statistics for all other data sets were calculated for the period 1981-2010. The monthly environmental data are averaged over the months July to October to correspond with peak TC activity in the WDR (Figure 1). For the purpose of comparison to prior seasons, the rank of each parameter is also calculated from the entire ERA-Interim reanalysis period of 1979-2014. Rank order is defined by anomaly values conducive to TC activity - hence, 1 would be the season most favorable for TC activity (negative anomalies for vertical wind shear, positive for relative humidity) and 36 the least favorable for tropical activity for atmospheric parameters (except SST whose least favorable rank is 33).

\section{Analysis of the $\mathbf{2 0 1 5}$ WDR TC Season}

Figure 1 shows WDR ACE for the climatological period of 1981-2010 and the ACE in 2015, both as a cumulative density function as well as by month. The 2015 season was slightly above average through the middle of August, and then the activity increased dramatically associated with three very strong TCs that tracked through the region (Kilo, Ignacio, and Jimena). The average 1981-2010 TC season tapers off after midSeptember, but in 2015, there was only a brief lull from mid-September to early October before another sharp increase in activity was observed. This increase in late-season activity was very rare climatologically and pushed the 2015 season to record levels. Most of the late-season ACE in 2015 was generated by Hurricane Olaf. When looking at ACE by month, the largest increases from climatology were observed in August (84 in 2015 versus 22 for the 1981-2010 climatology) and in October (47 in 2015 versus 6 for the 1981-2010 
(a)

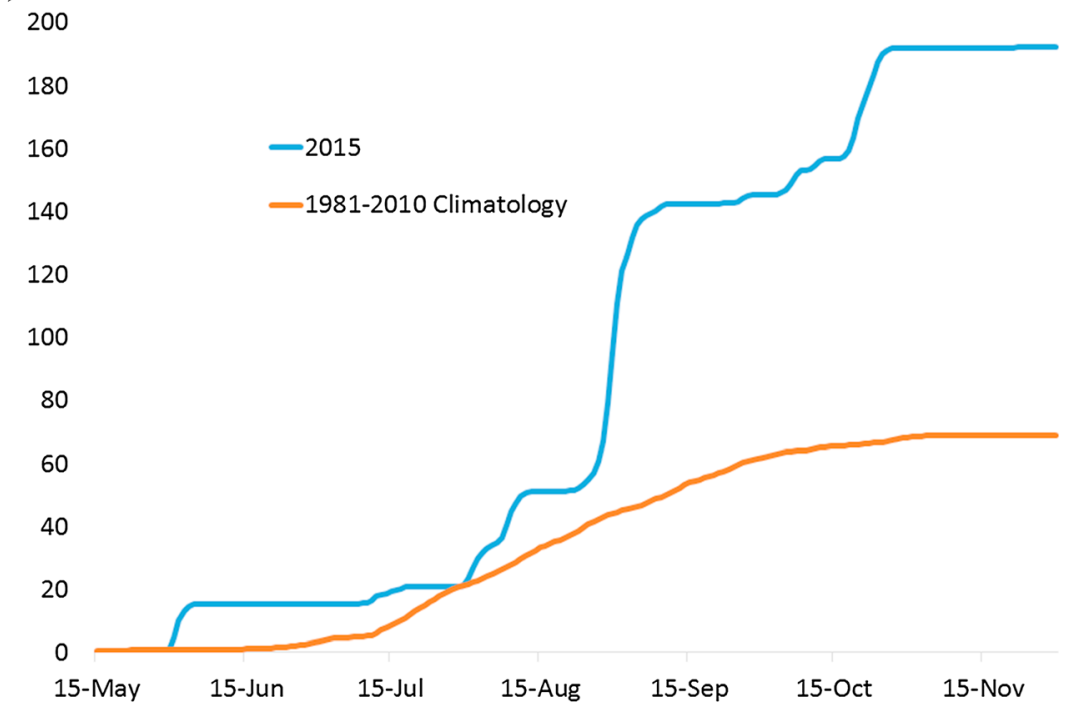

(b)

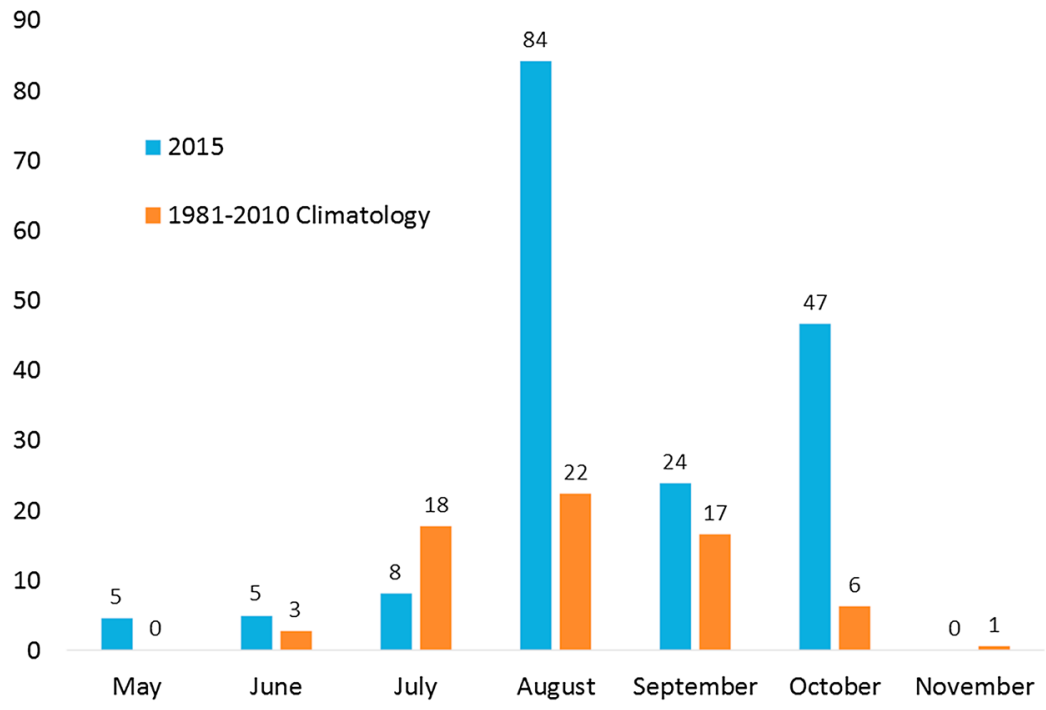

Figure 1. (a) Cumulative density function of Accumulated Cyclone Energy in 2015 (blue line) compared with the 1981-2010 climatological average (orange line), (b) Monthly Accumulated Cyclone Energy from May to November in 2015 (blue bar) compared with the 1981-2010 climatological average (orange bar).

climatology). Hereafter, we define the WDR hurricane season from July to October, as $95 \%$ of the $1981-2010$ climatological ACE that occurred during these four months.

The 2015 hurricane season occurred during a very strong El Niño event. This El Niño event was given a head start from the easterly wind burst that halted the 2014-2015 attempted El Niño, as well as the buildup of anomalous warm water volume generated from the early 2014 westerly wind bursts which remained throughout the boreal winter of 2014-2015 [Levine and McPhaden, 2016]. The July-October-averaged Multivariate ENSO Index (MEI) [Wolter and Timlin, 1998] was at its second highest level since 1979, trailing only 1997. The MEl is an ENSO index that takes into account not only SSTs but also surface pressure, cloud fraction, and zonal and meridional winds.

The Pacific Meridional Mode (PMM) [Chiang and Vimont, 2004], whose positive phase is characterized by warm SST anomalies across the WDR, was also positive during the 2015 hurricane season. The PMM was strongly positive (the third highest on record) during April-June of 2016, which helped sustain very warm 


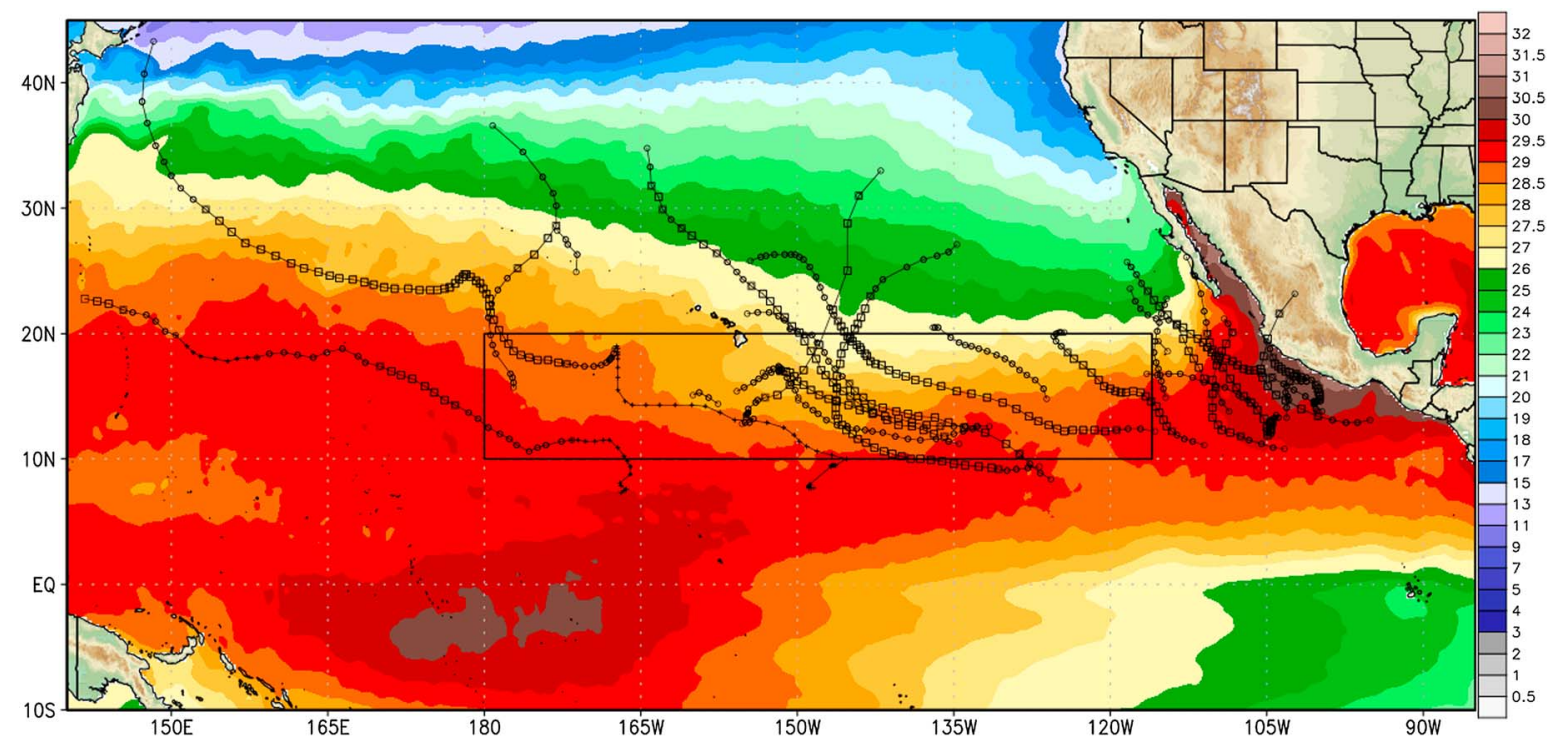

Figure 2. 2015 July-October average SSTs during an intense El Niño and the 2015 storm tracks (+= depression or low, o = 34 knots + , square $=64$ knots + ). The box represents the WDR.

SST anomalies that were present from the 2014/2015 winter due to a positive wind-evaporation-SST feedback [Chiang and Vimont, 2004]. Anomalous low pressure tends to form in tropical and subtropical regions with above average SSTs, and the associated circulation around the low-pressure area reduces the strength of the trade winds, suppressing evaporation and reinforcing the above average SST anomalies. The positive PMM persisted through the peak of the hurricane season, with the July-October-averaged PMM the sixth highest value since 1979 and 1 standard deviation above the 1981-2010 average. For reference, the most positive PMM value (since 1979) during July-October was 1992, which was also a very active hurricane season in the WDR. The combination of a very strong El Niño and a positive PMM led to record warm SSTs and an extremely active 2015 hurricane season across the WDR (Figure 2).

An examination of SST values shows that between July and September 2015, the majority of the WDR had a high percentage of days (between 80 and 100\%) with SSTs above $28.5^{\circ} \mathrm{C}$ (Figure 3a). This is in stark contrast to the climatological mean from 1983 to 2012 where over half of the WDR had less than $50 \%$ of days with these high temperatures (Figure 3b). These warmer, longer-lasting SSTs provided a much more conducive thermodynamic environment for TCs than is typical in the WDR during the hurricane season.

An analysis of the 2015 vertical wind shear anomaly between July and October compared to the 1981-2010 climatological mean (Figure 4) shows very low shear over a significant portion of the WDR region, particularly between $150^{\circ} \mathrm{W}$ and $180^{\circ}$. Here vertical wind shear anomalies are as much as 14-18 knots lower than climatology. The remainder of the WDR region is closer to the climatological mean, where shear is much weaker climatologically. These below normal values of vertical wind shear in the western part of the WDR allowed for many TCs to thrive in this region, an area where the environment is typically unfavorable for TC formation and intensification.

An examination of the average July through October values of the environmental variables in the WDR revealed not only more conducive conditions than normal but record-setting levels of conducive conditions for most variables (Table 1). July-October SSTs averaged over the WDR reached $28.6^{\circ} \mathrm{C}$, which ranked highest compared to all other years and the only year above $28^{\circ} \mathrm{C}$ in the data set. July-October-averaged vertical wind shear across the WDR was at its lowest levels on record. A combination of low wind shear and warm SSTs have been known for many years to create a much more conducive thermodynamic and dynamic environment for TC formation and intensification [Gray, 1979]. Likewise, precipitable water was at its highest levels, and sea level pressure was at its lowest levels during July-October in the WDR since 1979. $850 \mathrm{hPa}$ relative vorticity was at its highest level, and relative humidity $(500 \mathrm{hPa})$ was at its third highest level during JulyOctober in the WDR. Sea surface temperatures, $850 \mathrm{hPa}$ relative vorticity, total precipitable water, and sea level pressure were greater than 3 standard deviations away from their climatological average in a manner 
(a)

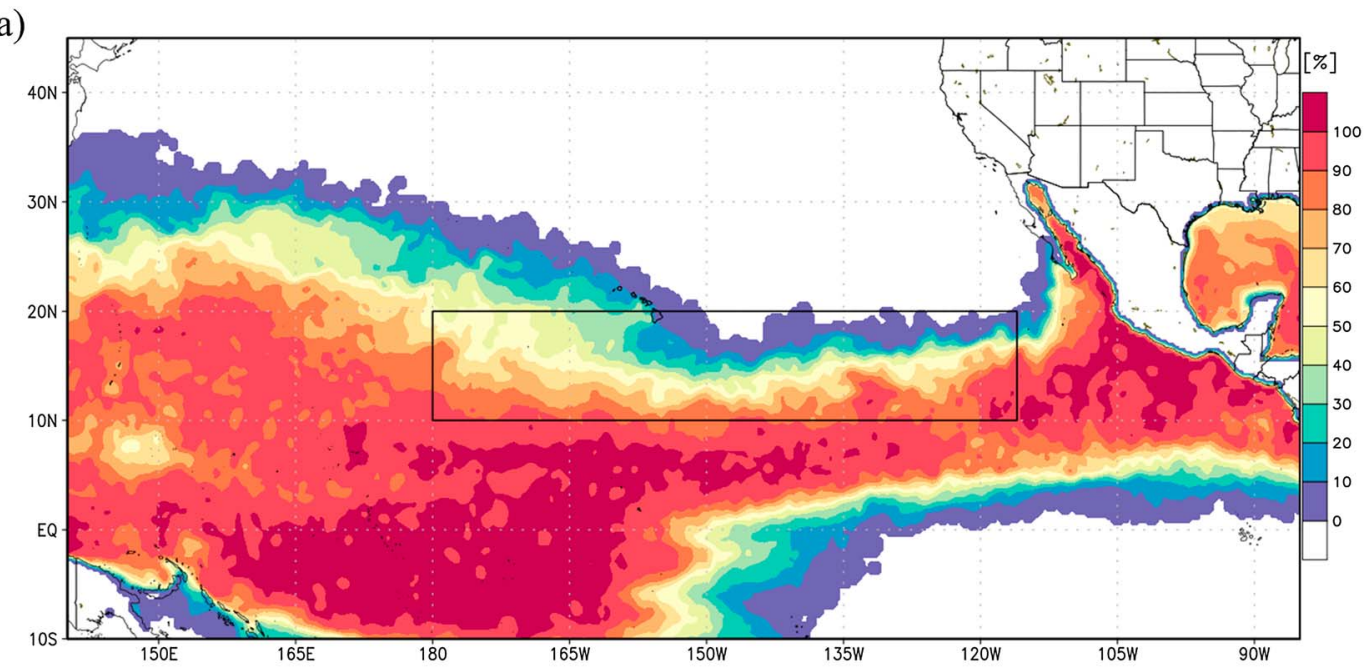

(b)

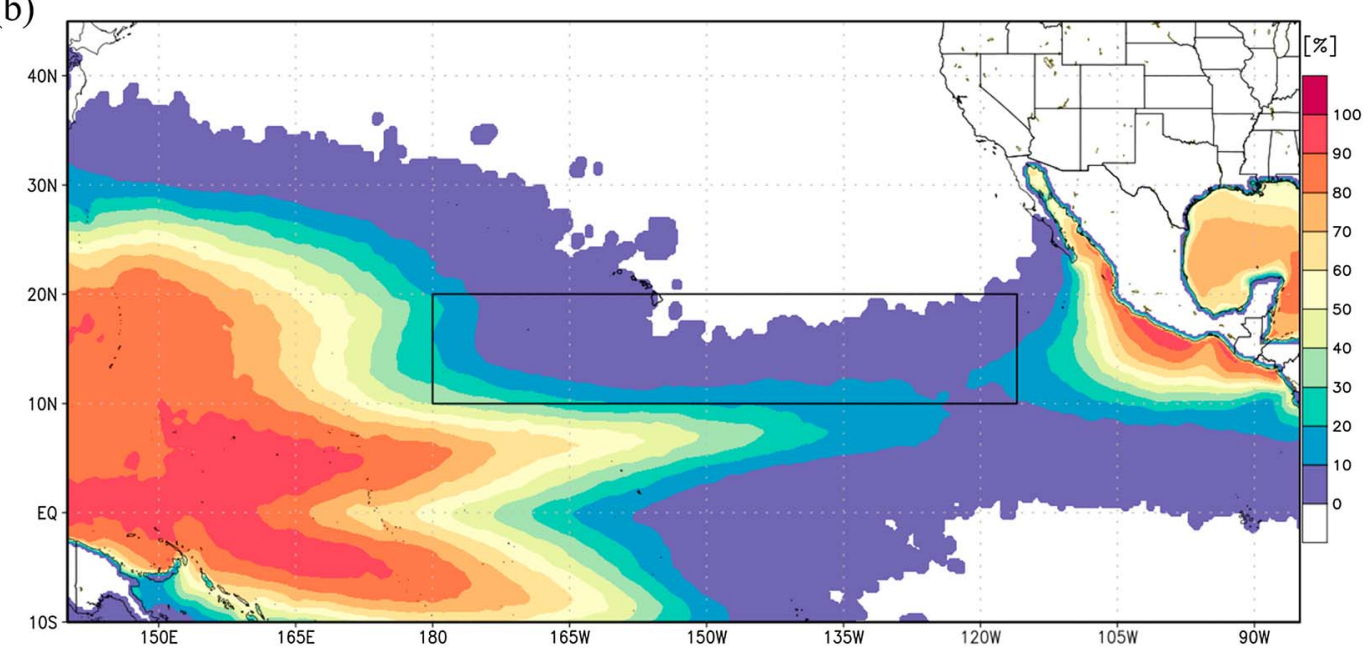

Figure 3. (a) Percentage of days with SSTs above $28.5^{\circ} \mathrm{C}$ in July through October in 2015. (b) Percentage of days with SSTs above $28.5^{\circ} \mathrm{C}$ in July through October during the climatological period of 1983-2012. The box represents the WDR.

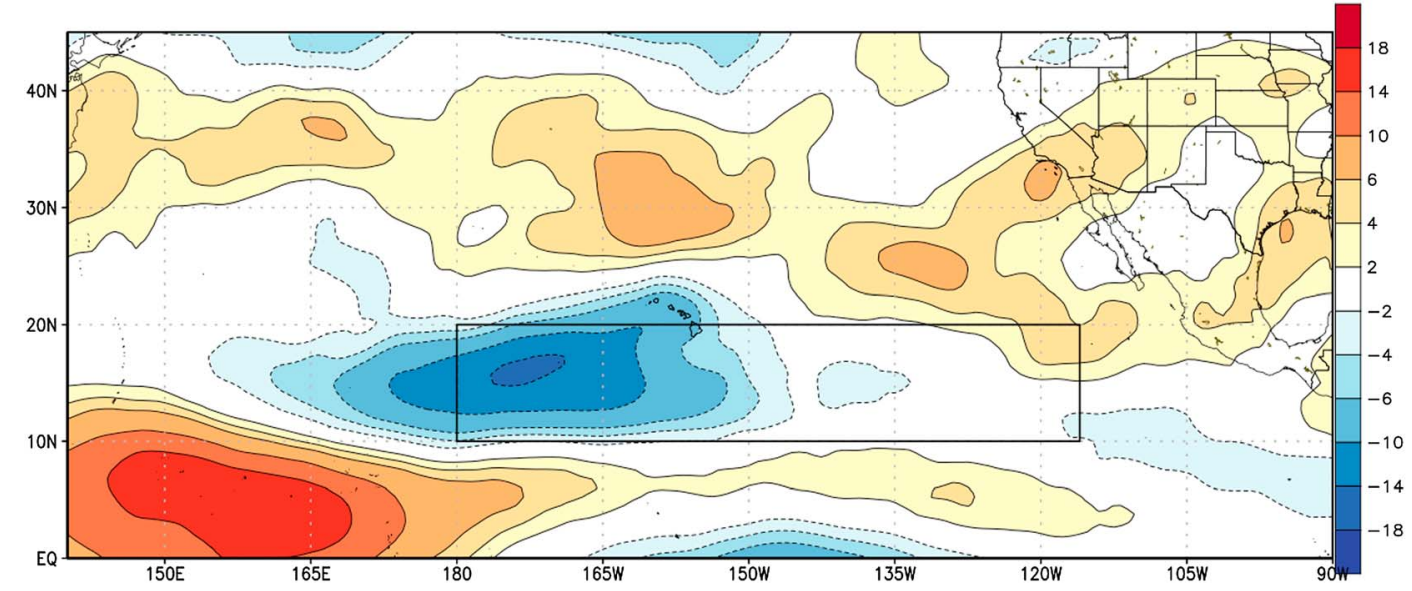

Figure 4. The 2015 vertical wind shear anomaly (in knots) between July and October compared to the 1981-2010 mean. The box represents the WDR. 
Table 1. July-October-Averaged Large-Scale Conditions Across the WDR in 2015, July-October Climatological Average Conditions, 2015's Rank Compared With All Seasons Analyzed and the 2015 Standardized Anomaly Relative to Climatology ${ }^{\mathrm{a}}$

\begin{tabular}{lcccc} 
Parameter & $\begin{array}{c}2015 \\
\text { Value }\end{array}$ & $\begin{array}{c}\text { Climatological } \\
\text { Average }\end{array}$ & $\begin{array}{c}2015 \\
\text { Rank }\end{array}$ & $\begin{array}{c}2015 \text { Standardized } \\
\text { Anomaly }\end{array}$ \\
\hline July-October SST ( $\left.{ }^{\circ} \mathrm{C}\right)$ & 28.5 & 27.2 & 1 & +3.9 \\
July-October $500 \mathrm{hPa} \mathrm{RH}(\%)$ & 42.0 & 33.9 & 3 & +1.7 \\
July-October $850 \mathrm{hPa} \mathrm{RV}\left(\mathrm{s}^{-1}\right) \times 10^{6}$ & 3.9 & 1.4 & 1 & +4.6 \\
July-October TPW $\left(\mathrm{kg} \mathrm{m}^{-2}\right.$ ) & 48.6 & 42.1 & 1 & +3.3 \\
July-October MSLP (hPa) & 1010.6 & 1012.4 & 1 & -3.2 \\
July-October Vertical Wind Shear $(200-850 \mathrm{hPa})(\mathrm{kts})$ & 9.9 & 16.8 & 1 & -2.6 \\
\hline
\end{tabular}

${ }^{\mathrm{a}}$ All ranks are listed with 1 being the most favorable for hurricane formation and intensification.

known to be conducive for hurricane formation, indicating extraordinarily conducive conditions. Overall, we would argue that the environment in the WDR during the 2015 hurricane season was the most favorable on record (since 1979). While we acknowledge that the TCs themselves may imprint on these signals, given the 4 month period analyzed, the large size of the WDR box, and the fairly crude ability of reanalysis products to resolve TCs, we believe that the TC imprint on these large-scale signals is fairly small.

\section{Intraseasonal Variability of TC Development in the WDR}

While the 2015 WDR hurricane season was extraordinarily active, very active periods were followed by periods of low TC activity. Several of these active periods occurred during convectively active pulses of the MJO (Figure 5), which have been shown to significantly impact central and eastern North Pacific TC activity [Maloney and Hartmann, 2000; Klotzbach and Blake, 2013; Collins and Roache, 2011]. However, the most active period of the WDR season in late August when Kilo, Ignacio, and Jimena reached Category 4 status simultaneously seemed to have little relationship with the MJO.

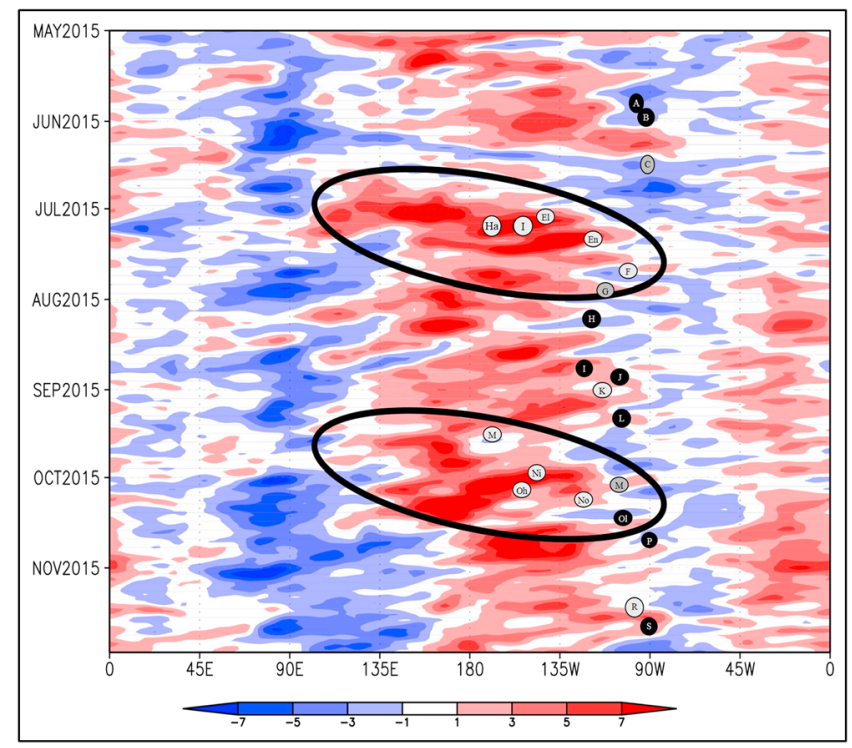

Figure 5. Hovmöller diagram of $850 \mathrm{hPa}$ zonal wind anomalies averaged from $7.5^{\circ} \mathrm{S}$ to $7.5^{\circ} \mathrm{N}$. Black ellipses highlight eastward propagation of the convectively active phase of the Madden-Julian Oscillation. The dots represent the point of tropical cyclogenesis for major hurricanes (black), hurricanes (dark grey), and tropical storms (light gray) with the corresponding letters of the storm name on the dot.
The background state was dominated by low-level westerly wind anomalies near the International Date Line, which is typical of strong El Niño events. Two coherent MJO events can be identified, as evidenced in eastward propagation of low-level westerly wind anomalies. Low-level westerly wind anomalies provide a more conducive environment for TC development in the WDR through a reduction in vertical wind shear as well as an increase in preexisting low-level vorticity.

The first MJO event in mid-July coincided with the development of TCS Ela, Halola, lune, Enrique, and potentially Guillermo. Although the MJO did not appear to play a significant role in modulating the development of the three Category 4 hurricanes during late August, the background El Niño state was favorable for TC formation during this time. We also note that the TCs that formed in late 
August were approximately $25-30^{\circ}$ of longitude apart from each other, so they did not destructively interfere with each other. An examination of convectively coupled Kelvin Waves (CCKW) revealed that the development of these three TCs in rapid succession was likely aided by a weak CCKW. While the base state was favorable, the CCKW likely served to focus the genesis times, with the precursors to Ignacio and Jimena becoming better organized after the CCKW passed.

The background westerly wind anomalies briefly weakened during the middle to latter part of September which may have been partially responsible for the inactive WDR period during that time. The second MJO pulse propagated across the WDR during early to mid-October coinciding with the TC formation of Oho, Niala, and Nora. Hurricane Olaf was a very intense late-season TC for the WDR and may have been enhanced by this second pronounced MJO pulse.

\section{Implications for Future Hyperactive Seasons}

One of the findings of this manuscript is that the strong El Niño created a very conducive thermodynamic and dynamic environment that fueled the active 2015 WDR season. The implication for the prediction of future hyperactive seasons in the WDR is raised, given that over $95 \%$ of WDR ACE occurs after June. The rank correlation between WDR ACE and the May-June-averaged value of the MEl is 0.56 from 1979 to 2015. The MayJune MEl was at least 0.5 standard deviations positive in 9 of the 10 most active WDR seasons since 1979, while 0 of the 10 least active WDR seasons since 1979 had a MEl that was 0.5 standard deviations or more positive. Consequently, simply knowing the value of the May-June-averaged MEl appears to provide for useful discrimination at predicting active versus inactive seasons in the WDR. We also investigated the potential of using the PMM as an additional predictor, but it did not appear to add additional discriminatory skill beyond that given by the MEl.

\section{Conclusions}

This article examines the large-scale environment that led to the record-breaking eastern North Pacific hurricane season. The focus of this manuscript was on the Western Development Region (WDR), which broke several records for TC activity levels in 2015. A very strong El Niño event combined with a positive Pacific Meridional Mode to generate an environment of record warm sea surface temperatures, record high lowlevel relative vorticity, record high precipitable water, record low vertical wind shear, record low sea level pressure, and anomalously high mid-level moisture. All of these conditions were documented in a variety of studies to create an environment much more conducive for TC genesis and intensification. The Madden-Julian Oscillation appeared to play a role in two of the heightened periods during the WDR season but seemed to play little role during the most active portion of the WDR season in late August, when three Category 4 hurricanes were present in the WDR simultaneously. Knowledge of the state of El NiñoSouthern Oscillation at the end of June appears to allow for predictability of active versus inactive seasons in the WDR.

Acknowledgments

The second author would like to acknowledge support from the G. Unger Vetlesen Foundation. We would like to acknowledge University of South Florida graduate student Daniel Gessman for adding TC positions to the MJO plot (Figure 5). Data specific to this paper are available at http://weathercenter.forest.usf.edu/faculty/

\section{References}

Bell, G. D., M. S. Halpert, R. C. Schnell, R. W. Higgins, J. Lawrimore, V. E. Kousky, R. Tinker, W. Thiaw, M. Chelliah, and A. Artusa (2000), Climate assessment for 1999, Bull. Am. Meteorol. Soc., 81, S1-S50.

Chiang, J. C. H., and D. J. Vimont (2004), Analagous meridional modes of atmosphere-ocean variability in the tropical Pacific and tropical Atlantic, J. Clim., 17, 4143-4158.

Collins, J. M. (2007), The relationship of ENSO and relative humidity to interannual variations of hurricane frequency in the north-east Pacific Ocean, Pap. Appl. Geogr. Conf., 30, 324-333.

Collins, J. M., and D. R. Roache (2011), The 2009 hurricane season in the eastern North Pacific basin: An analysis of environmental conditions, Mon. Weather Rev., 139, 1673-1682.

Collins, J. M., and I. M. Mason (2000), Local environmental conditions related to seasonal tropical cyclone activity in the northeast Pacific basin, Geophys. Res. Lett., 27, 3881-3884, doi:10.1029/2000GL011614.

Dee, D. P., et al. (2011), The ERA-Interim reanalysis: Configuration and performance of the data assimilation system, Q. J. R. Meteorol. Soc., 137, doi:10.1002/qj.828.

Gray, W. M. (1979), Hurricanes: Their formation, structure and likely role in the tropical circulation, in Meteorology Over Tropical Oceans, edited by D. B. Shaw, pp. 155-218, Royal Meteorological Society Press, Bracknell, England.

Klotzbach, P. J., and E. S. Blake (2013), North-Central Pacific tropical cyclones: Impacts of El Niño-Southern Oscillation and the Madden-Julian Oscillation, J. Clim., 26, 7720-7733.

Klotzbach, P. J., and C. W. Landsea (2015), Extremely intense hurricanes: Revisiting Webster et al. (2005) after 10 years, J. Clim., 28, 7621-7629. Landsea, C. W., and J. L. Franklin (2013), Atlantic hurricane database uncertainty and presentation of a new database format, Mon. Weather Rev., 141, 3576-3592, doi:10.1175/MWR-D-12-00254.1. 
Levine, A. F. Z., and M. J. McPhaden (2016), How the July 2014 easterly wind burst gave the 2015-6 El Niño a head start, Geophys. Res. Lett., 43 , 6503-6510, doi:10.1002/2016GL069204.

Maloney, E. D., and D. L. Hartmann (2000), Modulation of eastern North Pacific hurricanes by the Madden-Julian Oscillation, J. Clim., 13, $1451-1460$.

Molinari, J., D. Vollaro, S. Skubis and M. Dickinson (2000), Origins and mechanisms of eastern Pacific tropical cyclogenesis: A case study, Mon. Weather Rev., 128, 125-139.

Namias, J. (1954), Long range factors affecting the genesis and paths of tropical cyclones, in Proc. UNESCO Symp. on Typhoons, pp. 213-219, UNESCO, Tokyo, Japan.

Reynolds, R. W., N. A. Rayner, T. M. Smith, D. C. Stokes, and W. Wang (2002), An improved in situ and satellite SST analysis for climate, J. Clim. $15,1609-1625$

Wolter, K., and M. S. Timlin (1998), Measuring the strength of ENSO events-How does 1997/1998 rank?, Weather, 53, 315-324, doi:10.1002/ j.1477+8696.1998.tb06408x. 